\title{
DO FUNDO dA COZINHA AO REINO dE ABISSÍNIA: ETNOGRAFIAS, IMAGENS E NARRATIVAS
}

\author{
Ricardo Campos \& Peter Anton Zoett ${ }^{1}$ \\ CICS.NOVA \& CRIA-UM, Lisboa, Portugal
}

A revista Cadernos de Arte e Antropologia assumiu como missão trabalhar numa zona de fronteira, procurando diálogos e articulações entre aquilo que comummente classificamos como pertencendo quer ao domínio da estética, quer ao da epistemologia. Estas áreas longamente apartadas por tradições com identidades e modos de fazer distintos, têm sido chamadas, cada vez mais, a cooperar no quadro de uma alteração de paradigma que não é propriamente recente. Não podemos ignorar que, no caso das ciências sociais, modos de fazer originalmente associados ao campo estético e artístico, foram largamente empregues em empreendimentos etnográficos no século XIX e ao longo do século XX. Destas formas de cooperação surgiriam as subdisciplinas da antropologia e sociologia visuais, com graus de implantação e sucesso díspares.

Apesar do iconofobia da academia, há muito denunciada, e de alguma resistência que ainda persiste nalguns redutos, facto é que, atualmente, a imagem nas suas mais variadas vertentes (desenho, fotografia, cinema) tem sido bem acolhida no seio das ciências sociais. A sua gradual aceitação estará, certamente, associada a uma verdadeira democratização do acesso aos meios de produção e disseminação visual e a uma cultura contemporânea fortemente assente na imagem. Mas o mais curioso é que isto não explica o retorno que se sente, também, aos meios mais rudimentares e simples de produção de imagens, como, por exemplo, o desenho (etnográfico). Questionado o paradigma positivista e a crença na infabilidade e neutralidade da imagem técnica, surgem novas rotas possíveis para pensar a imagem, quer enquanto processo de produção de conhecimento, quer enquanto forma de construção de narrativas.

Verificamos, então, que o uso da imagem tem sido fundamental a vários níveis. Por um lado, para pensar o próprio processo de pesquisa e observação da realidade. $\mathrm{O}$ que nos traz o processo de produzir imagens, em termos de foco epistemológico? Esta interrogação é relevante para a pensar as ciências sociais hoje. Por outro lado, as imagens também têm sido consideradas na qualidade de dados analíticos, condensando informações sobre a realidade social e cultural, passíveis por isso, de análises mais finas. Por último, as imagens, numa época em que nunca

$1 \mathrm{O}$ trabalho dos autores é financiado pela Fundação para a Ciência e a Tecnologia (FCSHPTDC/SOCSOC/28655/2017 \& SFRH/BPD/99782/2014). 
antes se produziram tantas, assumem um papel de destaque na forma como comunicamos com diferentes públicos, particularmente com os não-académicos. Gostaríamos de salientar, precisamente, esta última vertente. Num período em que se incentiva uma maior permeabilidade das fronteiras que separam a academia da sociedade e a construção de saberes partilhados, a imagem pode deter um papel fundamental. Não apenas porque rompe com os discursos mais herméticos da academia, mas também porque se aproxima de plataformas de linguagem mais acessíveis e familiares a distintos públicos (o cinema, a banda desenhada/história em quadrinhos, o desenho, o multimédia, a fotografia, etc.). $\mathrm{O}$ que nos endereça, desde logo, para um outro debate sobre a diferenciação de técnicas e linguagens visuais, que incitam diferentes patamares de entendimento, de reflexão conceptual, mas também de usufruto estético. A banda desenhada, a colagem, o webdocumentário ou o hipermédia representam formas de comunicação diferentes e têm potenciais distintos em termos de comunicação científica e de promoção do pensamento antropológico.

Neste contexto, uma outra questão, igualmente considerada como central para os propósitos desta revista, merece ser destacada. Em que medida pode o campo das artes, nomeadamente das artes visuais no seu sentido mais amplo, contribuir para este debate, dando pistas sobre novas formas de olhar e questionar a realidade? Daí que tenhamos incentivado a participação de artistas com as mais diversas formações e experiências a contribuir para a revista. Ao longo destes oitos anos que decorreram desde o lançamento do primeiro número, tivemos diversas contribuições nesse sentido, nas secções de ensaios visuais ou etnoartes. Todavia, dada a sua relevância, quisemos dar especial protagonismo a estas expressões, dedicando um número especial aos ensaios visuais.

Podemos considerar que este dossiê foi um sucesso, não apenas pelo número de propostas que nos chegaram, mas também pela qualidade daquelas que efetivamente foram selecionadas para publicação. O presente número é uma boa mostra não apenas da diversidade de caminhos possíveis, mas também da riqueza das expressões estéticas. Temas como a morte, a religiosidade, a viagem, o culto religioso ou a alimentação, entre outros, serviram de base de trabalho e de expressão para os ensaios visuais que aqui apresentamos.

O dossiê abre com uma reflexão sobre "Desenho em Antropologia" de Jeferson Carvalho da Silva. O ensaio apresenta uma série de anotações, "rabiscos" e apontamentos retirados de diários de campo, que retratam como o autor construiu uma narrativa em torno de um terreno etnográfico aparentemente simples: a cozinha. Aprendemos, porém, que se trata de um ambiente em que as pessoas e os objetos se encontram inseridos numa constante dinâmica que atravessa diversos aspetos materiais e processos de significação. Como metodologia de pesquisa, o desenho permitiu ao autor não se fixar somente nas conceções estéticas dos traços, mas dar atenção aos vínculos que se estabeleceram no próprio terreno etnográfico, e às enunciações verbais dos seus informantes.

Numa outra vertente do desenho, Emily Thiessen apresenta uma forma incomum de fazer etnografia: o comic. O comic da autora, que se entende como representação principal da sua "auto-etnografia", nos leva a uma viagem de Victoria (Canada) até à cidade Xiamen, acompanhando a busca de Thiessen pelas suas origens familiares no sul da China. Enquanto o comic reflete sobre a dificuldade de encontrar o passado num mundo em constante desenvolvimento, o ensaio textual que o acompanha pondera as potencialidades do desenho na captura do lado emocional das experiências pessoais, e o feeling dos lugares com que essas se entretecem. 
Lanna e Luana Beatriz Lima Peixoto, com seu ensaio "Dentre: mulheres, plantas e imagens", abrem o campo das artes etnográficas ou etno-artes. Numa comunidade quilombola do Pará, na Ilha do Marajó, as autoras se debruçam sobre a relação de mulheres e plantas, tecendo um diálogo entre a antropologia e a arte. As 15 imagens do ensaio, elaboradas numa técnica mista que recorre a cianotipia e ao marrom Van Dyke, se inspiraram nos quintais das mulheres da comunidade - verdadeiras "ilhas de florestas" que se configuram, ao mesmo tempo, como lugares de cultivo para os "remédios da terra" e lugares de memória da comunidade. O ensaio demonstra a importância das plantas como objetos mediadores, que interligam as diferentes dimensões da vida das mulheres em torno de eixos fundamentais como a família, a comunidade, a doença, a cura e o sobrenatural.

O ensaio fotográfico de Octávio Sacramento e Rui Pilão também se situa no reino vegetal, dando destaque, neste caso, à espécie Castanea sativa. Os autores transformam em imagens a "febre da castanha" que anualmente perpassa a região da Terra Fria transmontana, no nordeste de Portugal. As fotografias do ensaio, que retratam a apanha das castanhas em cores saturadas que parecem impregnadas pelo intenso frenesim outonal, incorporam e expressam a atmosfera de uma paisagem única, tanto em termos naturais como sociais. Num diálogo com as fotografias, o ensaio presta especial atenção às sociabilidades, práticas laborais e disposições corporais que se manifestam na azáfama da apanha dos frutos da castanha, e a sua omnipresença na vida dos moradores.

Em contrapartida, o ensaio fotográfico de Marcelo Moura Mello trata de plantas não-comestíveis, enfocando o processo de confeção e circulação de guirlandas de flores em um templo hindu localizado na Guiana. Com a sua máquina fotográfica, o autor acompanha as conexões tecidas entre devotos e devotas da deusa Kali e as divindades, retratando a permeabilidade de ambos, e a forma como as flores ligam as ações das pessoas às divindades, sendo concebidas como manifestações divinas em corpos de humanos. O ensaio destaca as dimensões da troca, da transmissão de afetos e do cuidado no culto a Kali, buscando retratar os vínculos e as ligações que se estabelecem através das guirlandas de flores frescas.

Por seu turno, o texto de Manuel João Ramos faz uma incursão ao terreno etnográfico, debatendo o papel do desenho e do diário de campo enquanto elementos presentes no processo de pesquisa. Através de uma análise densa, debate-se o papel do desenho enquanto elemento indispensável à construção do conhecimento etnográfico, vinculado às memórias, às emoções e à vivência no campo. $\mathrm{O}$ acto de rabiscar, de esboçar algo numa folha de papel, é entendido como um acto individual e complexo, do ponto de vista mental e cognitivo. Esta discussão é acompanhada por um conjunto de imagens retiradas do seu diário visual, produzido numa pesquisa no norte da Etiópia em 2012. Deixamos um convite ao leitor para viajar através das excelentes imagens produzidas pelo autor.

Apresentando um conjunto de desenhos desenvolvidos entre 2001 e 2011, Isabel Baraona analisa a relação entre o desenho e o texto no trabalho plástico da própria autora, recorrendo a dois elementos principais: a casa e os corpos duplicados. Os desenhos da autora caracterizam-se pela sua natureza narrativa, entrelaçando diversos fragmentos de textos literários, contos de fadas e estórias infantis, bíblicas e mitológicas, assim como episódios autobiográficos. No seu ensaio, Baraona reflete sobre o processo de criação de imagens e o trabalho artístico que se constitui como uma cartografia de afinidades eletivas. 
O dossiê encerra com um olhar íntimo e sensível de Susana de Noronha sobre a experiência traumática de uma vítima de câncer. A partir de um tríptico de desenhos, a autora dialoga com a narrativa de "Flor", pseudónimo da mulher entrevistada, anos após a morte da sua mãe. Noronha interlaça conhecimento corporal, narrativa oral, desenho e teoria antropológica num texto que utiliza a metáfora e a imaginação para fazer entender o impacto que a doença e a morte exercem sobre as nossas vidas. O tríptico remete para o processo difícil de recriar a memória a partir de fragmentos, e a vontade de desfazer e refazer os pontos que a unem. A autora sugere uma visão performativa e epistemológica sobre as práticas artísticas, e a forma como estas nos permitem alargar os nossos conhecimentos em relação aos eventos marcantes da vida, e o modo como os relembramos. 